\title{
Correction to: Pore Space and Fluid Phase Characterization in Round and Angular Partially Saturated Sands Using Radiation-Based Tomography and Persistent Homology
}

\author{
Mohmad Mohsin Thakur ${ }^{1} \cdot$ Felix Kim ${ }^{1,2} \cdot$ Dayakar Penumadu $^{1} \cdot$ Anna Herring $^{3}$
}

Published online: 8 June 2021

(c) Springer Nature B.V. 2021

\section{Correction to: Transport in Porous Media (2021) 137:131-155 https://doi.org/10.1007/s11242-021-01554-w}

Unfortunately, the past affiliation of the author Felix Kim was missed in the original publication of the article. The correct affiliation is provided in this correction.

Publisher's Note Springer Nature remains neutral with regard to jurisdictional claims in published maps and institutional affiliations.

The original article can be found online at https://doi.org/10.1007/s11242-021-01554-w.

Mohmad Mohsin Thakur mthakur1@utk.edu

1 Department of Civil and Environmental Engineering, The University of Tennessee, 851 Neyland Drive, 325 John D. Tickle Building, Knoxville, TN 37996-2313, USA

2 Present Address: Intelligent Systems Division, National Institute of Standards and Technology, 100 Bureau Drive, Gaithersburg, MD 20899, USA

3 Department of Applied Mathematics, Research School of Physics and Engineering, Australian National University, Canberra ACT, 2600, Australia 